Article

\title{
Impacts of Recreational SCUBA Diving on a Natural Area in Puerto Vallarta, Mexico
}

\author{
Natalia Balzaretti Merino ${ }^{1}$, Myrna Leticia Bravo-Olivas ${ }^{2} * \mathbb{D}$, Rosa María Chávez-Dagostino ${ }^{2}$ \\ and Pedro Medina-Rosas ${ }^{2}$
}

1 Arts, Education and Humanities Department, Centro Universitario de la Costa, Universidad de Guadalajara, 48280 Puerto Vallarta, Jal., Mexico; natalia.balzaretti@cuc.udg.mx

2 Biological Sciences Department, Centro Universitario de la Costa, Universidad de Guadalajara, 48280 Puerto Vallarta, Jal., Mexico; rosac@cuc.udg.mx (R.M.C.-D.); pedro.medinarosas@gmail.com (P.M.-R.)

* Correspondence: myrna.bravo@cuc.udg.mx; Tel.: +52-3222-262-200

Citation: Balzaretti Merino, N.;

Bravo-Olivas, M.L.;

Chávez-Dagostino, R.M.;

Medina-Rosas, P. Impacts of Recreational SCUBA Diving on a Natural Area in Puerto Vallarta, Mexico. Sustainability 2021, 13, 6249. https://doi.org/10.3390/su13116249

Academic Editor: Colin Michael Hall

Received: 24 March 2021

Accepted: 18 May 2021

Published: 1 June 2021

Publisher's Note: MDPI stays neutral with regard to jurisdictional claims in published maps and institutional affiliations.

Copyright: (c) 2021 by the authors. Licensee MDPI, Basel, Switzerland. This article is an open access article distributed under the terms and conditions of the Creative Commons Attribution (CC BY) license (https:// creativecommons.org/licenses/by/ $4.0 /)$.

\begin{abstract}
Despite the protection status of the marine area in Los Arcos, it has experienced reef deterioration associated with tourism activities. Therefore, this study aimed to analyze SCUBA divers' impacts by quantifying and typifying their contact with the seabed, and to determine if the diving leader's performance is related to the behavior of the divers being guided. The number and type of impacts on the seabed were counted and categorized as intentional and non-intentional. A total of 9811 contacts were made by 101 divers. The highest frequency type of non-intentional contact identified was "lifting sediment", following by non-intentional—fins. The "hands" intentional contact type was found to occur most often. The highest frequency of total contacts per diver was "very high" (31.7\%). By analyzing the profile of the divers related to their certification level, number of dives, SCUBA center attended, and leader, it was possible to establish a relationship between the number of contacts made by the leader and the number of contacts made by the divers guided by each leader. Our findings suggest the need for a joint approach of key players toward good practices to highlight the important role of diving leaders on their clients' behavior, and thus preserve the ecological and aesthetic qualities of the dive site.
\end{abstract}

Keywords: SCUBA diving; tourism; responsible diving; reef

\section{Introduction}

Reefs benefit coastal communities by providing them with marine natural resources and allowing local economic diversification through tourism activities. SCUBA diving, despite slower growth following rapid expansion in the 1980s, has maintained a constant demand globally and consequently increased the demand on marine resources. The certification agency Professional Association of Diving Instructors (PADI) claims that it issued over 27,000,000 diver certifications globally since 1967. Furthermore, during the past 20 years, around 900,000 persons received a certification, either newly awarded or by continuing education [1].

Over time, however, activities such as SCUBA diving have contributed to the change of marine ecosystems [2], due to repetitive and cumulative contact that divers exert on the seafloor, as a result of incorrect SCUBA practices by divers, diving guides, and dive providers. Impacts include physical damage that, in the long term, could interfere in biological and ecological processes [3,4], and contribute to fragile or rare species loss [4,5]. Therefore, as SCUBA diving continues to increase in popularity, the risk of negative impacts is also increasing [5-7]. This compromises the achievement of sustainable development goals, particularly UN SDG 14 "life below water", which is related to the conservation and sustainable use of the oceans, seas, and marine resources for sustainable development [6-8].

The term "impact" has been defined in numerous ways, mostly to express a negative condition. Short-term impacts with intense episodes are referred to as a "pulse", whereas 
"pressure" relates to persistent and chronic impacts [9]. The intensity of the impact is related to the frequency or amount of use (for example, number of contacts), the type of use and associated behaviors, the season of use and the environmental conditions, and the location [10]. SCUBA diving is commonly referred to as having direct impacts that can be easily perceived [11] and physical impacts that leave a mark [12,13], such as breaking or moving something from the seabed. Thus, both pulse and pressure are applicable to SCUBA diving.

As a measure to ensure that diving is sustainable over the long term, it is essential to maintain non-detrimental levels of use in marine ecosystems [14,15], and improve practices among SCUBA diving staff and divers. Thus, SCUBA diving tourism must be examined and managed from a holistic perspective, within the three elements proposed by Dimmock and Musa [16]: environment, divers, and business. Using this approach, researchers and stakeholders jointly design the measures for responsible SCUBA diving tourism mainly based on the limit of acceptable change for each site.

Studies at sites with high levels of diving activity, i.e., between 30,000 and 250,000 SCUBA divers per year, have noted the need to control and prevent the negative effects of diving on marine ecosystems $[17,18]$. Nonetheless, at sites such as Cabo Pulmo, on the tip of Baja California Peninsula in Mexico, reef deterioration has been reported; this has occurred despite a moderate flow of divers (4482 in 2011), equal to a total carrying capacity of $4.7 \%$ [19]. Several researchers noted that understanding the perception, preferences, and profiles of diving centers [11] and divers [20,21], and divers' motivations [22], experience, interpretation, meanings [23], satisfaction [24], and underwater behavior [25] could help identify the different motivations that lead divers to have repetitive physical contacts with the seafloor [26]. This information is fundamental to create effective management strategies at each site [27-30] to counteract the damage already caused and prevent future damage. These strategies are based on improving training content and techniques for divers [31-33] and dive centers [34], knowledge of the behavior of species in the presence of divers [8,35], and how these species change their behavior. It is also important that management protection of underwater cultural and natural resources by government administration is accompanied by an emphasis on education [26], outreach, and support for local communities [36]. Studies on SCUBA diving impacts have shown negative effects on different kind of ecosystems, mainly coral reefs, highlighting the importance of controlling the frequency and type of impacts caused by SCUBA divers on marine life, such as loss of coral cover [14,37], changes in species behavior [8,38], and landscape changes [39]. Thus, it is necessary to identify specific physical characteristics and marine organisms at each site, to take adequate preventive measures [40], implement responsible practices in SCUBA diving [41], and analyze SCUBA divers' behavior at popular diving hot spots.

The methods undertaken to identify the impacts of SCUBA diving vary significantly regarding the observation time of the divers, the number of observers, the tools used to count the contacts, and the collected information about divers. Lucrezi et al. [42], for example, assessed SCUBA diving activities to evaluate the contact behavior of SCUBA divers, SCUBA divers' contact rate, and the type of contact with various substrates and wildlife. Their design consisted of underwater observations of SCUBA divers via videotaping performed by three observers, and a post-dive questionnaire given to divers. The size of the observed groups did not exceed 12 divers. Divers were not informed of the aim of videotaping the dive to prevent behavioral changes during observation. The observers worked at a distance of $5 \mathrm{~m}$, the dive was undertaken between 12 and $40 \mathrm{~m}$, and observations lasted 15-20 min, including time at the beginning and end of the dive. It was acknowledged at the end of the study that this fragmentation may not have been ideal. This design exemplifies decisions that researchers must make depending on the site being studied, objectives, equipment, and available personnel.

As stated by Roche et al. [43], the types of studies and strategies to reduce the environmental impacts of SCUBA diving can be summarized in four main groups: (1) regulate the diving sites; (2) restrict the number of divers; (3) regulate the type of equipment allowed; 
and (4) programs to regulate the provision of diving services. In contrast to the first three of these, few studies have focused on improvement of the diving process in which the role of the instructor or guide is central. Although some researchers have identified a relationship between impacts, experience, gender [44], and pre-dive briefing [2], this issue remains unresolved.

A general emerging proposal is to focus on reef management at the local scale, instead of addressing global cumulative stressors that cannot be controlled, such as global climate and ocean change [45]. One of the aims of this study is to contribute to the debate, particularly related to the role of instructors or guides from dive centers at the local scale.

Puerto Vallarta, Mexico, is an international beach destination and the location of a group of islets and rocky formations known as Los Arcos. Los Arcos is a natural marine area that was declared a protected refuge for marine flora and fauna in 1975 due to its ecological richness and scenic beauty [46], and is currently recognized as an area for SCUBA diving. Despite its protected status, at least in principle, previous research has identified reef deterioration associated with fishing and tourism activities [47-50]. However, little scientific information from the area is available, despite the tourism pressure on the site. Therefore, this research aimed to analyze SCUBA divers' impacts by quantifying and typifying divers' contacts with the seafloor in the natural marine area of Los Arcos, Mexico, and analyze if the SCUBA diving leader's performance is related to the behavior of the divers they guided. The proposed research questions are as follows: What are the types and extent of the intentional and non-intentional contacts of the divers with different elements of the seabed at Los Arcos? What is the role of the SCUBA guides in the behavior of the divers? Is there any difference by gender in the type and number of impacts? What are the management implications for the area related to SCUBA divers?

\section{Study Area}

Los Arcos is located in Jalisco, in the central Mexican Pacific (Figure 1), a transition zone influenced by the cold current of California and the Gulf of California from the north, and the warm current of Costa Rica, as part of the northwestern current coming from the south. These currents combine to produce a region of high biodiversity [51].

Los Arcos comprises five islets with an approximate total area of 30 hectares [49] and height of up to $9 \mathrm{~m}$. Two of the islets have rocky arch formations through which people and boats can pass. The seabed is comprised of a sandy and rocky floor [51], with algae patches and coral. The topography presents different forms, such as lifts or deep canyons, pinnacles, and long formations of slopes connected to plains. Diving sites here vary in topography and types of marine floor; these characteristics contribute to the sites' attractiveness. Compared to other areas in the Banderas bay, Los Arcos has the highest tourism and fishing pressure, combined with greater species richness and density [52].

In 1975, the government promoted the protection of natural areas with tourism potential, and Los Arcos was declared a refuge of marine flora and fauna. In 1997, Medina-Rosas noted that the main damage caused to the coral was by tourist activities [49]. Later, Aranda-Mena observed a decrease in fish species richness, mentioning the importance of implementing a management plan to regulate tourism [47]. In 2001, Medina-Rosas and Cupul-Magaña [48] noted that only 5\% of coral was alive. However, in 2008 RamírezCordero established that the area was significantly underutilized relative to its carrying capacity despite tourist activity such as SCUBA diving, which was considered to contribute to the damaging effects observed at the site [50].

The main tourist activities at Los Arcos are kayaking, paddle boarding, snorkeling, swimming, free diving, and SCUBA diving. Aquatic services providers have used specific locations for each activity, providing a more organized setting. Currently, there are five SCUBA diving zones, which are usually used as marine trails, known by divers as The Aquarium, Devil's Canyon, Christ Pinnacle, Lajas, and The Wall (south zone). These paths are preferred by diver providers because they possess major concentrations of fish species, such as manta rays (Mobula birostris), eagle rays (Aetobatus laticeps), zebra moray 
(Gymnomuraena zebra), starry moray (Echidna nebulosa), king angel fish (Holacanthus passer), yellow fin surgeon (Prionurus punctatus), Moorish idol (Zanclus cornutus), pacific seahorse (Hippocampus ingens), cornetfish (Fistularia commersonii), and sablefish (Ablennes hians), in addition to marine turtles, such as the carey turtle (Eretmochelys imbricata).

\section{Los Arcos}
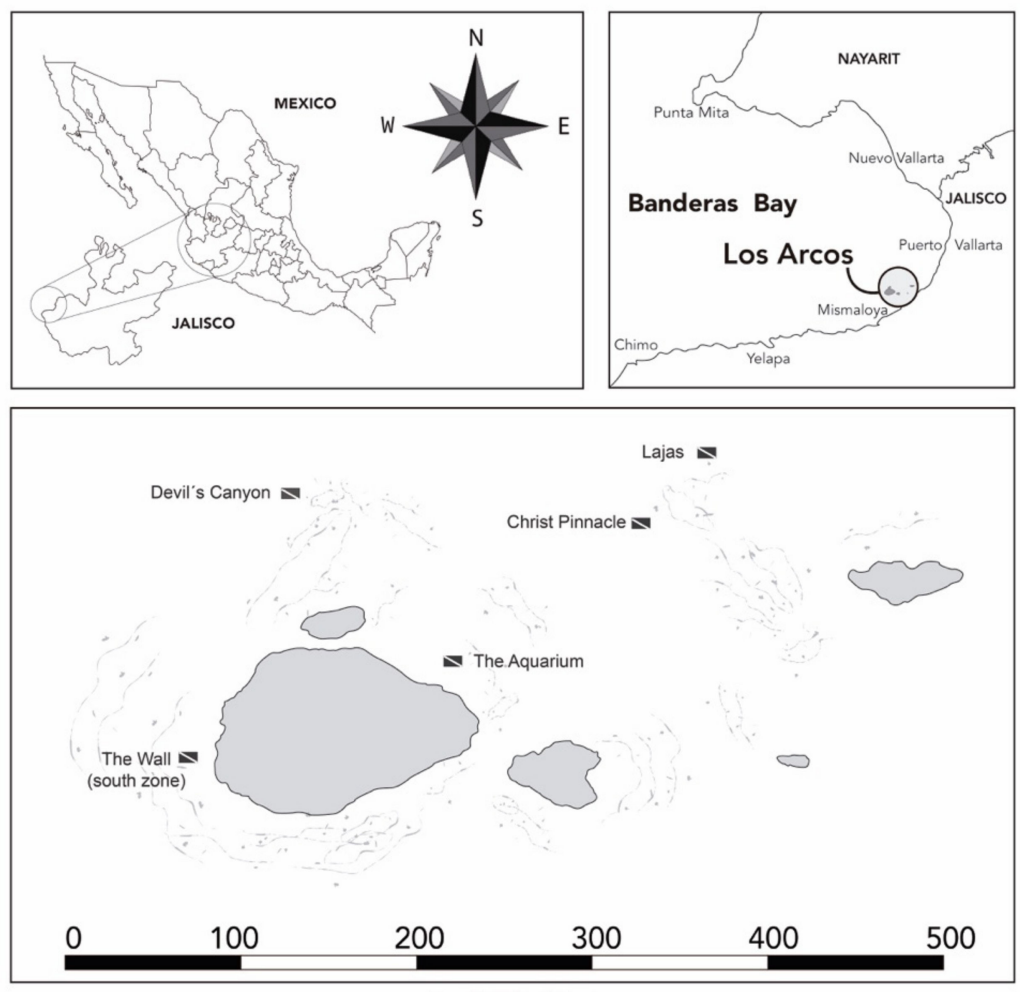

1: 200 Meters

Figure 1. Location of Los Arcos. Source: Own elaboration based on Medina-Rosas \& Cupul Magaña [48].

\section{Materials and Methods}

Data were collected from divers and diving centers between April and November 2018 to typify and quantify divers' impacts in a mixed cross-cutting study, with an explanatory depth level. The aim was to determine the SCUBA diving practices affecting Los Arcos and the reason for these effects.

\subsection{Divers Profile}

Permission to join SCUBA group dives as an external observer was requested of diving centers that were identified as operating at Los Arcos, to record underwater video and interview the divers following the activity, on board their boat. Once they accepted, the divers were informed before the activity that a study regarding diving practices was taking place and its purpose. Then, we invited divers to participate, and asked for their consent to be video recorded during the activity and to complete a questionnaire following the dive. Because the divers were used to being photographed underwater, they did not feel uncomfortable with the procedure.

Following the dive, each diver was informed about the specific aim of the research and the video recording, and was asked to complete a questionnaire, for which they indicated agreement to participate by ticketing a box. Only the groups and divers that agreed to collaborate were included in the study. The survey included 12 closed questions that encompassed demographic data, service satisfaction, dive site perception, diver provider, 
and diver profile. The data collection protocol and survey were approved by the Ethics Committee from Centro Universitario de la Costa of the University of Guadalajara.

These data allowed us to relate divers' profiles and the contact frequency of divers. Using descriptive and inferential statistics, data analysis was carried out (SPSS version 25).

The sample size was estimated based on the 3300 visitors who dived at Los Arcos in 2017. This data was collected from 17 SCUBA centers that frequently visit the site: 13 of these are local to Puerto Vallarta and four are based in other cities; however, only seven agreed to be observed. This resulted in a sample of 101 SCUBA divers (confidence level of $95 \%$ and error level of 10\%) [53] who were observed directly and completed the survey.

The sampling approach used for direct observations (DO) was the cluster type [54], using random selection (there was no prior information or inference about the profile of the divers who carried out the activity).

To identify each SCUBA center, the letter $C$ with a number corresponding to the order that was given on the DO was assigned. We followed the same process with the diving leaders but used the letter $\mathrm{G}$ with a number. To facilitate their identification during underwater observation, divers were assigned a color on their tank, which allowed us to relate individuals to their questionnaire.

\subsection{Number and Type of Impacts}

To analyze SCUBA divers' impacts, an external diver directly observed and filmed divers' behavior throughout the dive [42], counting the number and type of impacts of the divers on the seabed $[26,37,40,42,55]$. The divers were aware of the presence of an external diver, who maintained a distance between 2 and $5 \mathrm{~m}[42,55]$ from the party. The party was asked by their guide to remain close, so the external diver appeared to be in the party. Diver behavior was observed with an average visibility of $12 \mathrm{~m}$ and video was used to record the complete $35 \mathrm{~min}$ bottom time; this was established with the diving leaders before diving and the 3 min safety stop was not considered. To facilitate observation, when diving groups numbered greater than four, in addition to the guide, then half were observed during the first dive and the other half during the second dive. This was possible because diving centers usually offer two dives on each trip to Los Arcos. Group sizes ranged from 1 to 8 divers.

Total bottom dive time was recorded to ensure a varied topography and distinct type of substrate, exposing divers to different characteristics of the seabed during the trails and allowing comparison with other studies $[7,26,37,40]$. Nevertheless, other stress factors related to the divers' performance, such as visibility, sea current, water temperature, wind, consistency of the seabed, and SCUBA gear familiarity, were not part of the assessment to qualify divers' behavior.

A compact video camera GoPro ${ }^{\circledR}$ Model 4 Silver, configured with $4 \mathrm{~K}$ quality, $60 \mathrm{fps}$, Wide FOV $17.2 \mathrm{~mm}$, and an external red filter, was used to record divers' behavior [42]. The camera was mounted to a monopod stick held by the external diver during the dive.

This diver had the opportunity to follow the groups for the entire course, and each contact or specific behavior was observed and recorded on video, which facilitated subsequent counting $[2,56,57]$. After each dive, the videos were analyzed to quantify the number of contacts made by each diver; this analysis was carried out by two researchers at different times. Then, the results of each researcher were compared to determine the consistency of the analysis criteria used by the two researchers. If any difference was found, both divers rechecked the video at the same time and unified the criteria.

A total of 25 diving groups, 33 immersions, 1155 min of dive time, and 101 SCUBA divers from seven diving centers were analyzed. The groups were always guided by a divemaster or instructor, respecting the ratio between diver leader and divers, their experience, visibility, and trail complexity level, according to the Mexican government [46] and PADI standards [58].

Data were collected, differentiating intentional and non-intentional contacts, based on Jadot et al. [59], in which a double contact was considered when any kind of direct contact 
was observed with the seabed and, at the same time, sediment was lifted. The contact frequency was further categorized by body limb, SCUBA gear, or improper action. In the following, the term "impact" means an improper action or direct contact by a diver with the seabed [12,46]. Intentional contacts were defined as divers who had buoyancy control and decided to voluntarily touch the seabed or any substrate element, for example, to move closer to a species or hold a rock to take a photograph. Non-intentional contacts were defined as those made by divers who did not have buoyancy control and thus could not avoid touching the seafloor or any substrate element, and, additionally, divers who were neutrally buoyant who made unintentional contact using any equipment or body parts.

The data were analyzed according to the total intentional and non-intentional contacts. The frequency was based on the number of contacts per diver proposed by Harriott et al. [7], similar to other studies $[21,26,37,40,60]$. The classification and corresponding values are shown in Table 1.

Table 1. Qualitative value assigned by contact frequency.

\begin{tabular}{|c|c|c|c|c|c|}
\hline Contact Frequency & $0-20$ & $21-40$ & $41-60$ & $61-100$ & $\geq 101$ \\
\hline Value assigned & "Null" & "Low" & "Medium" & "High" & "Very High" 1 \\
\hline
\end{tabular}

During the DO, some SCUBA leaders showed casual behavior during the dive, such as poor buoyancy control, non-corrective actions, and multiple contacts with the seabed. Thus, the following question arose: Does the dive leader have an effect on the divers' performance? To answer this question, a $\mathrm{X}^{2}$ test was performed [61].

\section{Results}

\subsection{Divers Profile}

Within the demographic data, the most frequent age group for SCUBA divers corresponds to $31-40$ years (26.7\%), and the age with the lowest presence was $41-50$ years $(8.9 \%)$. Regarding the gender, male divers were higher (62.4\%), compare to females.

Regarding the origin of divers, a higher percentage of national divers $(57.4 \%)$, compared to foreigners, mainly from the USA and Canada. Dominant nationals' age range was 31-40 years old and foreigners were between 51-60 years old.

The level of satisfaction of the divers was $100 \%$ positive, however, five of the seven centers received suggestions to improve some points, including: "receive more information from the site" (15.8\%), "diving equipment" (11.9\%), "logistics" (7.9\%), "punctuality" (6.9\%) and "security" (1\%).

Most of the divers received information before diving (85.1\%), however, during DO the briefing information was focused mainly on the diving plan with emphasis on safety. National divers were the ones who most frequently mentioned the lack of site information during the briefing.

\subsection{Quantity and Type of Contacts Exerted by SCUBA Divers on Seabed}

A total of 9811 contacts were quantified from 101 SCUBA divers, with 334 corresponding to intentional and 9477 to non-intentional.

The highest frequency contact identified was in the non-intentional category of "lifting sediment", with 6559 incidents, followed by non-intentional-fins, with 2357 contacts. Among intentional contacts, "hand" was ranked first, with 159 contacts, followed by "fin", with 79 contacts (Table 2). 
Table 2. Frequency of contacts by object.

\begin{tabular}{cccc}
\hline \multicolumn{4}{c}{ Contacts by Object } \\
\hline Intentional & \multicolumn{2}{c}{ Non-Intentional } \\
\hline $\begin{array}{c}\text { Body Part or Equipment } \\
\text { on Contact }\end{array}$ & Frequency & $\begin{array}{c}\text { Body Part or Equipment } \\
\text { on Contact }\end{array}$ & Frequency \\
\hline Fin & 79 & Fin & 2357 \\
Tank & 0 & Tank & 18 \\
Pressure gauge & 5 & Pressure gauge & 160 \\
Camera & 14 & Camera & 3 \\
Hand & 159 & Hand & 100 \\
Knee & 44 & Knee & 279 \\
Lifting sediment & 0 & Lifting sediment & 6559 \\
\hline
\end{tabular}

Within the total contact frequency classification for each diver, the condition "very high" presented the highest percentage (31.7\%), representing almost one-third of the divers observed. However, the "null" frequency of 0-20 contacts accounted for a small percentage $(21.8 \%)$, which shows that some divers have good practices (Figure 2).

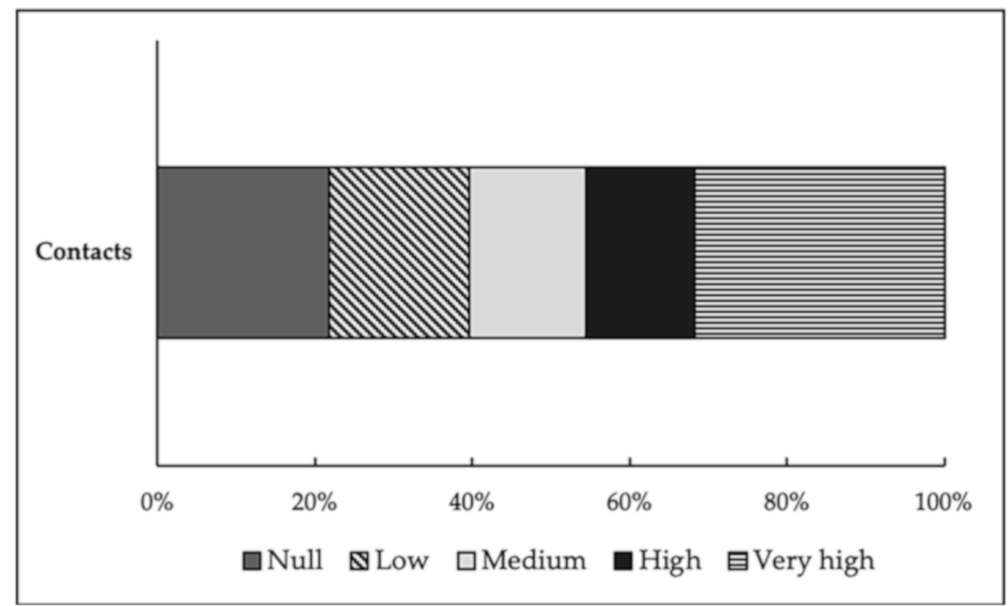

Figure 2. Percentage of total contacts by each diver.

Regarding gender, the average number of contacts among men was 109, which is within the "very high" category. By comparison, women averaged 75 contacts, corresponding to the "high" 61-100 frequency (Figure 3).

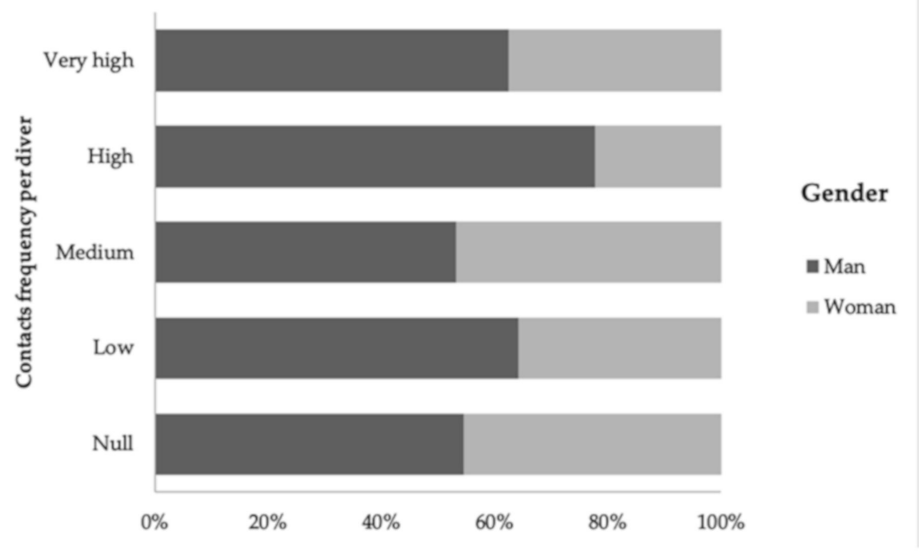

Figure 3. Total frequency contacts related to gender per diver. 
The certification level and the number of dives in males and females corresponded to beginner, particularly Open Water (OW), with fewer than 15 dives. Although the divers may have been beginners, good practices should not be neglected, implying that contact should not be made with the seabed.

Regarding the observed diving centers, more than one-third of their divers were found to be make high-frequency contacts $(\mathrm{C} 1-3, \mathrm{C} 6)$, in contrast to just one diving center (C4) that had a higher percentage of divers in the low-contact frequency (Figure 4).

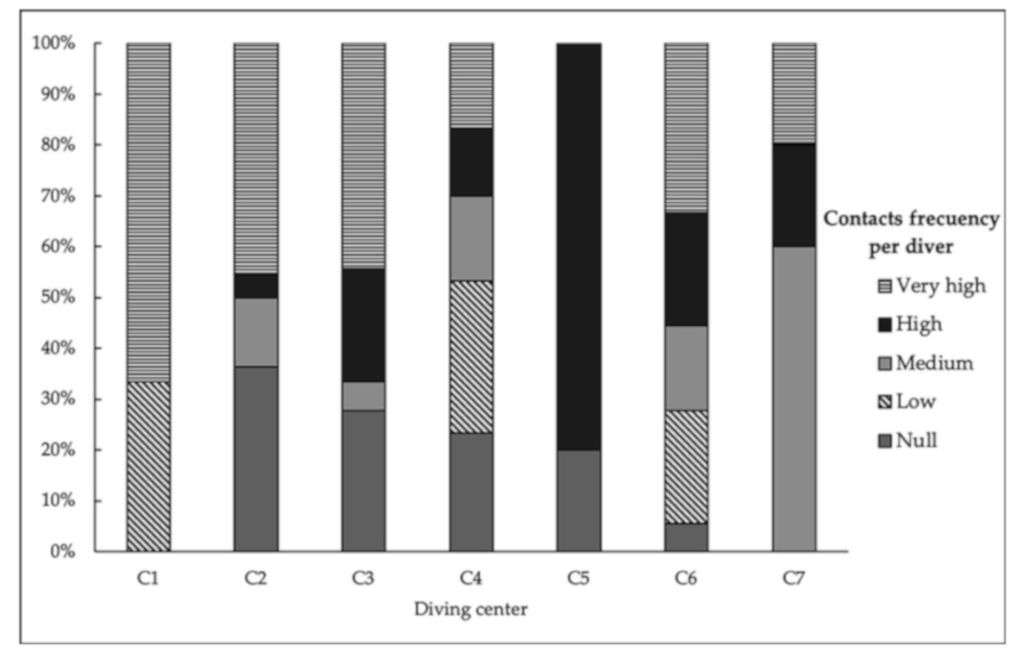

Figure 4. Contact frequency per diver per diving centers.

However, it was noted that some diving centers had more than one divemaster or instructor, who presented different individual contact frequencies, in addition to their SCUBA divers (Table 3).

Table 3. Total contact frequency classified per dive center, dive leader, number of divers that each leader guided, average total contacts per divers on the group and the average of contacts that each leader made.

\begin{tabular}{cccccc}
\hline $\begin{array}{c}\text { SCUBA } \\
\text { Center }\end{array}$ & Leader & $\begin{array}{c}\text { Divers' } \\
\text { Number }\end{array}$ & $\begin{array}{c}\text { Total-Contacts } \\
\text { per Diver }\end{array}$ & $\begin{array}{c}\text { Average Contacts per } \\
\text { Diver in the Group }\end{array}$ & $\begin{array}{c}\text { Average Total } \\
\text { Contacts Leader }\end{array}$ \\
\hline C1 & G1 & 3 & 302 & 101 & 10 \\
C2 & G2 & 13 & 1623 & 125 & 95 \\
C3 & G3 & 18 & 2134 & 117 & 38 \\
C2 & G4 & 9 & 259 & 27 & 0 \\
C3 & G5 & 4 & 32 & 8 & 5 \\
C3 & G6 & 4 & 1008 & 252 & 30 \\
C4 & G7 & 24 & 1599 & 67 & 0.5 \\
C5 & G8 & 5 & 337 & 67 & 11 \\
C4 & G9 & 6 & 201 & 34 & 0 \\
C6 & G10 & 10 & 547 & 55 & 1 \\
C6 & G11 & 2 & 106 & 53 & 0 \\
C7 & G12 & 5 & 462 & 92 & 20 \\
\hline
\end{tabular}

Similarly, only SCUBA divers of three leaders corresponded to "very high" frequency contacts, and only the divers of one leader remained completely within the "null" frequency (Figure 5).

Most leaders guided a variety of divers, although some were not experienced divers with more than 61 dives (three leaders). One leader had no beginner divers (with fewer than 15 dives), and two only had beginners (Figure 6). This could generate a disparity with other guides, however, the contacts did not necessarily correspond to their diving profile (Figure 5). 


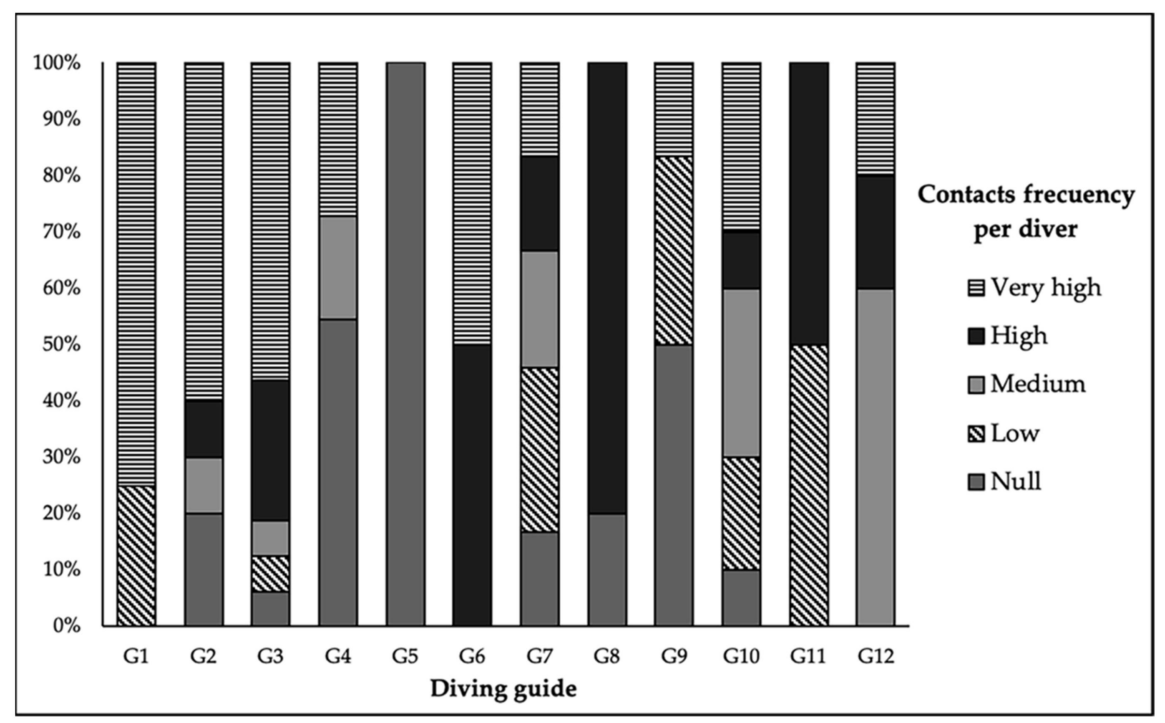

Figure 5. Relationship between leaders and total contact frequency of their SCUBA divers.

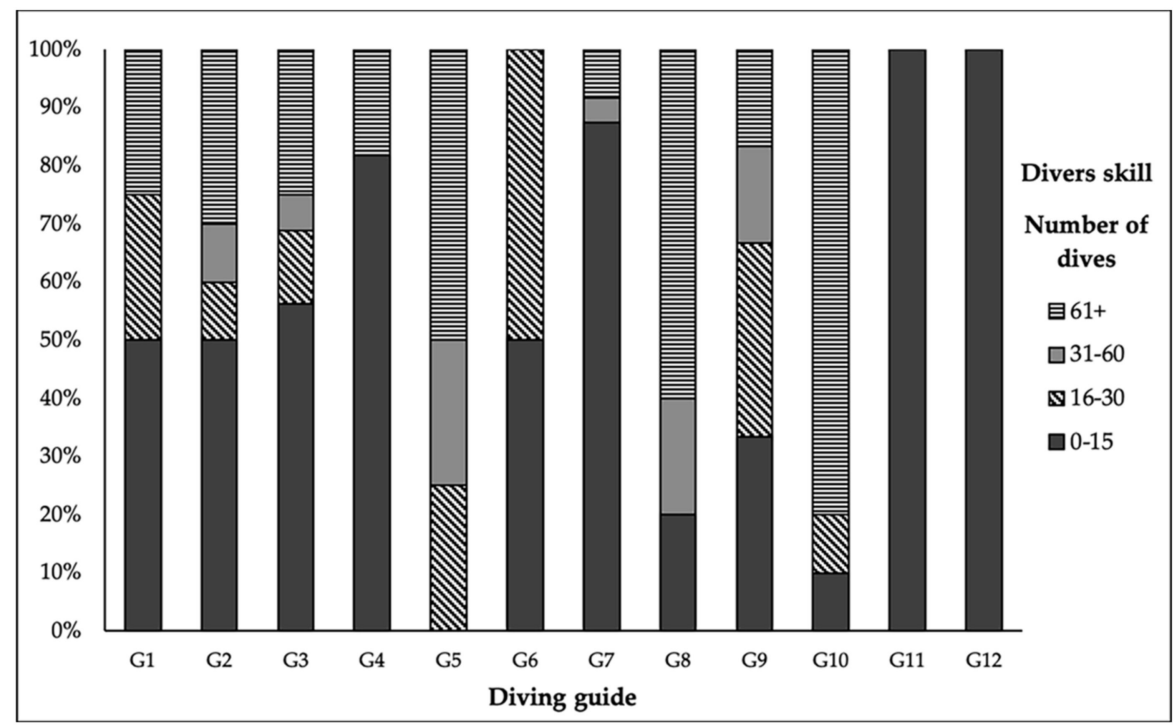

Figure 6. Relationship between leaders and SCUBA divers skills they guided.

Although some SCUBA divers had the necessary knowledge to perform good practices according to their certification level, not all were found to comply with it (Table 4).

Table 4. Average contacts per diver based on their certification level, and frequency of contacts value.

\begin{tabular}{ccc}
\hline Certification Level & Average Contacts for SCUBA Diver & Contact Frequency Value \\
\hline DSD $^{1}$ & 149.2 & Very High 101+ \\
OW & 104.6 & Very High 101+ \\
ADV & 36.38 & Low 21-40 \\
RESC & 53.33 & Medium $41-60$ \\
DM & 5 & Null 0-20 \\
INST & 468 & Very High 101+ \\
\hline
\end{tabular}

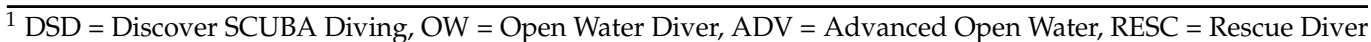
$\mathrm{DM}=$ Dive Master, INST $=$ Instructor.

Analysis of the diver profiles related to their level certification, number of dives, diving center, and diving leader showed that the number of contacts exerted by SCUBA divers was associated with the dive leaders $\left(X^{2}=93.6, p>0.05\right)$. 
Divers presented a range of frequency contacts from 0 (as "null") to "very high". Within this last frequency, the numbers varied between 101 and 592 contacts per diver. As a consequence, the number of contacts per SCUBA diver resulted in an average of 97 total contacts for a 35 min dive; this corresponded to the "high" frequency and was close to the limit of the "very high" frequency.

\section{Discussion}

To reduce the impact caused by incorrect diving practices, it is necessary to identify the factors that determine SCUBA divers' behavior and their effects on the environment. This could be useful for developing more effective training procedures, in addition to implementing management regulations at particular dive sites and preventive strategies [60]. Diver behavior, according to Ong and Musa [62], relates to the concern and attitude of divers, in which an "ecocentric" vision expected in pro-environmental behavior is represented by a lack of contact with the seabed during a dive. As a first step, the present study evaluated the relationship between factors that directly influence SCUBA divers' behavior during the dive, such as the type of contact they made with the seabed and the contact frequency, how these are directly linked to divers' profiles, and how they can affect the long-term health of the reef [63]. We concluded that the role of the diving leader in guiding the party is related to the number of contacts. Additionally, it would be of interest to assess the general environmental concern (attitude) among divers and relate this to the number of contacts to determine whether an "ecocentric vision" is related to impacts and, more importantly, if the role of the leaders could have management implications.

In this study, it was observed that almost all SCUBA divers had some kind of contact with the seabed during the dive. In previous studies, the contact frequency was similar to that of our findings (between $80 \%$ and $90 \%$ ): for example, in Ryukyu Islands in the Japanese Archipelago, where the bottom is mainly covered by coral [26]; in the rocky, artificial, and coral reefs of Abrolhos Brazil [40]; in coral reefs and sandy beds at Sierra Helada in the Mediterranean Sea [63]; in dive locations in the Philippines [43]; and in freshwater environments, such as groundwater in Iceland [64].

Three types of studies have been conducted in terms of the recording time: (1) a small portion of the dive, typically between 10 and $15 \mathrm{~min}$ [21,60,63]; (2) a longer portion of the dive, between 30 and $45 \mathrm{~min}[7,26,37,40]$; and (3) the entire immersion, in order to reinforce the observation [42]. This research surpassed these results for the total contacts of all divers observed and average total contacts per diver. This difference could be explained by the time considered for the estimation.

This study registered a total number of 9811 contacts. This was higher than in other studies, such as in Cape Byron and Solitary Islands in New South Wales, Australia, where 400 SCUBA divers were observed and 2974 contacts with the sea bottom were registered [21], representing $69.7 \%$ fewer contacts than recorded in the current study. This could be because both sites in Australia are Marine Parks, in which rules and management strategies are established. Additionally, the observation and sampling periods were different. In Australia, the DO was only performed for $15 \mathrm{~min}$, compared to $35 \mathrm{~min}$ at Los Arcos. However, even if the average observation time of both studies is accounted for, the result of the contacts of the present study remains superior $(>80 \%)$.

In the present study, we estimated that each diver made an average of 97.13 contacts in a 35 min dive. This was high compared to many other studies, which have reported an average of 10 to 20 contacts [21,26,37,40,60]. However, two studies had similar numbers to those in the current study. One of these was conducted in a Mediterranean marine protected area, with total contacts averaging 41.20 during $10 \mathrm{~min}$ of observation; the second study registered 35-121 contacts during a 30 min dive in marine protected areas in eastern Australia [7,63] (Table 5).

The SCUBA diver profile is a variable that should be taken into account because, in studies in which high contact rates were found, the highest contact percentage corresponded to beginners. To understand divers' profiles, certifications represent knowledge, 
experience, and skills acquired by SCUBA divers. In general, the level recognized by PADI coincides with the certifiers. At the basic level, the Discover SCUBA Divers (DSD) program corresponds to a level that does not require exhaustive training and does not provide a certification; this level only provides a short experience of breathing underwater. The DSD has to be performed in confined waters that are considered to be safe sites, such as small coves, with flat, shallow, and sandy bottoms, and a maximum depth of $12 \mathrm{~m}$.

Table 5. Average contacts per minute in this study, compared to others.

\begin{tabular}{|c|c|c|}
\hline Source & Observation Time & Average Contacts per Minute \\
\hline Hammerton [21] * & $8 \mathrm{~min}$ & 1 times $/ \mathrm{min}$ \\
\hline Toyoshima \& Nadaoka [26] & $30 \mathrm{~min}$ & 0.53 times $/ \mathrm{min}$ \\
\hline Worachananant et al. [2] * & $10 \mathrm{~min}$ & 1.6 times $/ \mathrm{min}$ \\
\hline Chung et al. [37] * & 25.8 average dive & 0.56 times $/ \mathrm{min}$ \\
\hline Giglio et al. [40] * & $30 \mathrm{~min}$ & 0.26 times $/ \mathrm{min}$ \\
\hline Jadot et al. [59] & $10 \min$ & 0.54 times $/ \mathrm{min}$ \\
\hline Harriot et al. [7] & $10 \mathrm{~min}$ & Between 1.16 and 4.03 times $/ \mathrm{min}$ \\
\hline Luna et al. [63] * & $10 \mathrm{~min}$ & 4.12 times $/ \mathrm{min}$ \\
\hline Present study* & $35 \mathrm{~min}$ & 2.77 times $/ \mathrm{min}$ \\
\hline
\end{tabular}

Open Water (OPW) is the first level that all certifiers recognize, and provides the necessary knowledge to dive safely. The diver is also always accompanied. Advanced Open Water (ADV) is the post-OPW certification level, in which more knowledge is provided; in addition, five specialties are required to accredit this level. Rescue Divers (RESC) is the third level, in which sufficient rescue, prevention, and safety knowledge is acquired to help other SCUBA divers, in addition to reinforcing the knowledge acquired in previous levels. Divemaster (DM) is the level at which supervisory knowledge is acquired. The role of leader or guide is taken. At minimum of 60 dives is required; from this level, the training is professional. Open Water Instructor (INST) is the level at which teaching knowledge is acquired to certify the aforementioned levels; at least 60 logged dives and 100 overall dives are required [65]. However, although divers may advance their certification level, the present study showed that they do not necessarily improve their practices; for example, the only instructor who was observed as a client had the highest frequency contacts in this study. Environmental concern was positively related to responsible behavior in Ong and Musa's study [25], in which they stated that knowledge has a significant effect on the behavior of the divers.

It is worth mentioning that studies with low values, between 10 and 20 contacts per dive, were focused on variables that improved good practices, such as the importance of pre-dive briefings, buoyancy control, and understanding of diver behavior $[26,37,40]$.

Therefore, from the comparisons undertaken in the current study, we established that SCUBA divers' profiles are not a determining factor in the application of good practices. If correctly exercised, good practice will result in fewer contacts because, although the divers may be beginners, with the necessary tools (knowledge and practice) they can reduce underwater damage. This kind of research should provide important information to conserve dive sites within their sustainability limits, and support decision making for future management plans.

It is of paramount importance to work in conjunction with dive centers. This study found that the dive site information provided to divers was not sufficient to understand the importance of good practices. A good pre-immersion briefing by guides and instructors, combined with a good example in front of dive groups, showed different results, as found in the case of the studies of Hammerton [31] and Toyoshima and Nadaoka [26]. In the first case [31], a group of divers without special training in buoyancy control was observed, and 
the contacts ranged from 0 to 23 . After a training period they were observed again, and contacts decreased ( $0-4$ contacts during 15 min of observation). In contrast, in the second case [26], the first analysis showed no differences because there was no extra training following the initial briefing. Therefore, the authors divided participants into two groups: divers with buoyancy control and those who did not have this skill. As a result, a significant difference was noticed. After obtaining the necessary information, divers with buoyancy control changed their behavior and made fewer contacts. In contrast, those without control showed no difference because they did not have the necessary tools to make a change.

When typifying contacts, similarity can be seen with other studies $[26,37,40]$, in which the involuntary uplift of sediment caused by fins was the most common type of contact, confirming that poor buoyancy control of divers is related to their profile. The case of the Ryukyu Islands, Japan [26], showing a direct relationship between the diver's profile and the type of contact. The highest values were for fin and sediment elevation. This was also the case in a study conducted in Hong Kong [37], in which the greatest number of contacts were made with fins. However, in the case of intentional contact, the most frequent type of contact was made with the hand, although this contact caused the least damage. In this study, inexperienced divers with fewer than 15 dives, in addition to the experienced group with more than 61 dives, voluntarily touched the seabed with their hand. In most cases, inexperienced divers had poor control underwater, which led them to touch with the hand to regain control, or they touched the seabed due to curiosity. In the case of experienced divers, contact was motivated by their confidence and comfort underwater, and also the desire to see something more closely.

According to the experience of divers, research conducted by Lucrezi, Milanese, Cerrano and Palma concluded that SCUBA diver experience is a useful tool to predict divers' behavior and a suitable basis for management decisions [66].

As observed in this study, improper diving practices can generate physical impacts on the landscape and marine community. Thus, adequate buoyancy control (neutral), a correct finning technique (such as the "frog kick"), good trim (body position) [31], and ecosystem awareness in divers and their leaders should be incentivized during training and diving tours.

During this study, it was noted that divers passing through sandy areas raise sediment, similar to findings in an Iceland freshwater environment [64]. In addition, divers passed through areas in which algae were present, causing breakages and damage due to repeated fin contact with the seabed. However, it should be noted that marine ecosystems are also affected by other factors of anthropogenic origin, such as pollution and global warming [67], and natural influences, such as the effects of El Niño and La Niña. Thus, it is difficult to determine the degree of damage in the corresponding ecosystem specifically derived from SCUBA diving activity. However, these impacts should not be ignored; rather, strategies should be developed to help mitigate and reduce any impact on the marine community caused by diving activity [19].

Studies by Krieger and Chadwick and Santander Botello showed that unsustainable diving practices can damage the ecosystem by decreasing coral cover [14,39]. Coral is not solely affected, with other specimens such as Mollusca, Arthropoda, Echinodermata, and Chordata experiencing decreases in their population. Research conducted in El Salvador by Barraza [68], and in the Mediterranean by Di Franco, Baiata, and Milazzo, observed changes in fish behavior [35]. Titus, Daly and Exton, in Honduras, noted that the high presence of divers interrupted the normal activity of fish at cleaning stations [8]. As was concluded in the review of Giglio, Luiz and Ferreira, cumulative negative impacts on benthic organisms can alter the structure of physical organisms and reef dynamics, and may make organisms less resilient to other effects such as climate change [45].

The number of contacts cannot be solely considered the only cause of damage because the origin of damage is multifactorial. However, a permanently stressed system is more vulnerable to negative impacts and cumulative effects can cause significant localized reduc- 
tion of coral cover [69]. Due to difficulties in addressing specific stressors in ecosystems, a common recommendation is to focus on area management at the local level [70].

Gender and diving impacts have been evaluated around the world with diverse results and interpretations. Some authors have identified a relationship between gender and the number of contacts or "touches" on the reef; Rouphael and Inglis established that male divers cause significantly more damage because they are more likely to interact with the reef and less likely to follow instructions [60]. They subsequently found that female divers were more likely to touch the substrate, and this finding has been supported by other authors [44]. These differences have been explained in terms of differences in physical capacity and ability to handle the equipment, rather than concern [2], and it has been found that divers' gender does not influence the frequency of reef interactions [55]. Although we found a higher contact average among males, we agree that this can be explained by differences in ability and physical capacity, and can also be related to other factors such as diver training and education.

In addition to restricting the number of divers allowed in a location relative to its carrying capacity, regulating the diving locations (trails) or the permitted equipment is a common strategy to improve the management process [43]. However, the role of the guide in supervising and correcting diver behavior has also been found to significantly reduce the contact rate per diver [43,71]. Thus, the management strategies at Los Arcos to reduce the number of contacts and possible damage should focus on the companies and guides, more than the divers. As suggested by Roche et al. [43], a frequent mechanism to reduce the number of diver contacts is the briefing before the dive, which could be improved, not just to provide information, but also to incentivize responsible diver behavior and highlight the environmental value of Los Arcos.

\section{Conclusions}

In the present study in Los Arcos, Mexico, all divers touched the seabed at least once, and the highest percentage of divers had more than 100 contacts. Non-intentional sediment lifting was the most frequent type of contact, followed by finning contact, which corresponded to the poor buoyancy control of divers regardless of their level of experience. This reflects insufficient diver training and poor knowledge of the value of the area, in addition to the lack of corrective actions performed by the guides and instructors during the dive. Nonetheless, women made fewer contacts than men, despite having similar training and diving in the same environment. The results of this study indicate that the training and supervision provided to divers are insufficient, particularly related to technical facts such as buoyancy control and fin position, which affect divers' performance, exhibited by repetitive contacts on the seabed. The diving practices carried out in Los Arcos are dive training activities at different levels of certification, recreational dives for species sighting, and scientific research; without adequate supervision and practices, these practices could increase contact and impacts on the seabed [26,31].

There is a lack of studies regarding the sediment impacts on corals caused by SCUBA divers. Further research is needed to expand baseline data on sediments and marine ecosystems. However, we also acknowledge the limitations of the research resulting from a lack of biological data and evidence.

Key to the adequate management of diving activity are the guides (diving leaders) and diving instructors, because these individuals can ensure that divers perform optimally, respect the ecosystem, and have less impact on the seabed. If diving activity is to continue, its impacts and their consequences must be minimized to maintain the ecosystem functions and underwater beauty, thereby maintaining the interest of visitors. Therefore, participation of dive centers and diving leaders within the area management plan should be considered, to create an enabling environment in which they are recognized as playing a role in improving the management performance. 
The number and type of contacts and damage caused by divers on the marine community are directly related to the service provider, SCUBA divers' experience, and their level of certification.

Our findings at Los Arcos provide a guide to management strategies on how to balance economic development through the non-extractive use of marine resources, such as diving and conservation in natural areas.

For future studies, we recommend including two divers as external observers to reduce blind points; the observers can simultaneously record the complete dive from each side, enabling the two cameras' views of the complete scene of divers' contacts to be compared. For this study, only half of the identified SCUBA centers that take divers to Los Arcos agreed to participate in the surveys. Although the 101 participating divers represented a confidence level of $95 \%$ and an error level of $10 \%$, this lack of participation could be another limitation.

We suggest including diving centers and local government institutions in the research team to obtain greater cooperation and more representative results. This participation would also contribute to more inclusive resource management in the area in terms of co-management. Participation of local communities in conservation has gained momentum in the past decade and can be considered to be an opportunity [72]. Co-managed protected areas may be generally more effective in meeting biological and socio-economic objectives although local perceptions of inequity may remain. It appears key to us that management plans are implemented, with rules of use, zoning of the area, and short- and long-term ecological monitoring programs to identify any alterations to species behavior or reef health, in addition to a section that outlines scuba diving monitoring and good practices.

Author Contributions: Conceptualization, N.B.M. and R.M.C.-D.; Formal analysis, N.B.M., M.L.B.-O. and R.M.C.-D.; Investigation, N.B.M.; Methodology, N.B.M., M.L.B.-O. and R.M.C.-D.; Writingoriginal draft, N.B.M. and M.L.B.-O.; Writing-review \& editing, N.B.M., M.L.B.-O., R.M.C.-D. and P.M.-R. All authors have read and agreed to the published version of the manuscript.

Funding: This research received no external funding.

Institutional Review Board Statement: The study was conducted according to the guidelines of the Declaration of Helsinki, and approved by the Ethics Committee of Centro Universitario de la CostaUniversity of Guadalajara (protocol code 058-2017, approved on 18 December 2017).

Informed Consent Statement: Informed consent was obtained from all subjects involved in the study.

Data Availability Statement: The data presented in this study are available on request from the corresponding author. The data are not publicly available due to their containing information that could compromise the privacy of research participants.

Acknowledgments: Balzaretti Merino gratefully acknowledges the scholarship from National Council for Science and Technology to pursue her Master's degree (grant number 483323). We thank dive shops and agencies that allowed us to track divers in Los Arcos.

Conflicts of Interest: The authors declare no conflict of interest.

\section{References}

1. PADI. 2019 Worldwide Corporate Statistics Data for 2013-2018; PADI: Rancho Santa Margarita, CA, USA, 2019.

2. Worachananant, S.; Carter, R.W.; Hockings, M.; Reopanichkul, P. Managing the Impacts of SCUBA Divers on Thailand's Coral Reefs. J. Sustain. Tour. 2008, 16, 645-663. [CrossRef]

3. Bravo, G.; Márquez, F.; Marzinelli, E.M.; Mendez, M.M.; Bigatti, G. Effect of Recreational Diving on Patagonian Rocky Reefs. Mar. Environ. Res. 2015, 104, 31-36. [CrossRef]

4. Hammerton, Z. SCUBA-Diver Impacts and Management Strategies for Subtropical Marine Protected Areas; Southern Cross University: East Lismore, Austrilia, 2014.

5. Kenchington, R.A.; Hudson, B.E.T. Man's threat to coral reefs. In Coral Reef Management Handbook; Kenchington, R.A., Hudson, B.E.T., Eds.; UNESCO: Jakarta, Indonesia, 1988; pp. 171-178. ISBN 92-3-102485-X.

6. Lucrezi, S.; Saayman, M. Sustainable scuba diving tourism and resource use: Perspectives and experiences of operators in Mozambique and Italy. J. Clean. Prod. 2017, 168, 632-644. [CrossRef] 
7. Harriott, V.J.; Davis, D.; Banks, S.A. Recreational Diving and its impact in Marine protected areas in eastern Australia. Ambio 1997, 26, 173-179.

8. Titus, B.M.; Daly, M.; Exton, D.A. Do Reef Fish Habituate to Diver Presence? Evidence from Two Reef Sites with Contrasting Historical Levels of SCUBA Intensity in the Bay Islands, Honduras. PLoS ONE 2015, 10, e0119645. [CrossRef]

9. Bender, E.A.; Case, T.J.; Gilpin, M.E. Perturbation Experiments in Community Ecology: Theory and Practice. Ecology 1984, 65, 1-13. [CrossRef]

10. Priskin, J. Tourist perceptions of degradation caused by coastal nature-based recreation. Environ. Manag. 2003, 32, 189-204. [CrossRef] [PubMed]

11. Rátz, T.; Puczko, L. The Impacts of Tourism: An Introduction; Häme Polytechnic: Hämeenlinna, Finland, $2002 ;$ ISBN 9517840594.

12. Gilpin, A. Environmental Impact Assessment (EIA): Cutting Edge for the Twenty-First Century; Cambridge University Press: Cambridge, UK, 1995; ISBN 0521429676.

13. DOF-Diario Oficial de la Federación. Ley General del Equilibrio Ecológico y la Protección al Ambiente; Congreso de los Estados Unidos Mexicanos: Ciudad de México, Mexico, 2018; p. 135.

14. Krieger, J.R.; Chadwick, N.E. Recreational diving impacts and the use of pre-dive briefings as a management strategy on Florida coral reefs. J. Coast. Conserv. 2013, 17, 179-189. [CrossRef]

15. Pendleton, L.H. Environmental quality and recreation demand in a caribbean coral reef. Coast. Manag. 1994, $22,399-404$. [CrossRef]

16. Dimmock, K.; Musa, G. Scuba Diving Tourism System: A framework for collaborative management and sustainability. Mar. Policy 2015, 54, 52-58. [CrossRef]

17. Hasler, H.; Ott, J.A. Diving down the reefs? Intensive diving tourism threatens the reefs of the northern Red Sea. Mar. Pollut. Bull. 2008, 56, 1788-1794. [CrossRef] [PubMed]

18. Zakai, D.; Chadwick-Furman, N.E. Impacts of intensive recreational diving on reef corals at Eilat, northern Red Sea. Biol. Conserv. 2002, 105, 179-187. [CrossRef]

19. Álvarez del Castillo Cárdenas, P.A. Capacidad de Carga Turística por Buceo en el Parque Nacional Cabo Pulmo; Instituto Politécnico Nacional, Centro Interdisciplinario de Ciencias Marinas: La Paz, Mexico, 2012.

20. Giglio, V.J.; Luiz, O.J.; Schiavetti, A. Marine life preferences and perceptions among recreational divers in Brazilian coral reefs. Tour. Manag. 2015, 51, 49-57. [CrossRef]

21. Hammerton, Z. Determining the variables that influence SCUBA diving impacts in eastern Australian marine parks. Ocean Coast. Manag. 2017, 142, 209-217. [CrossRef]

22. Wong, K.M.; Thirumoorthy, T.; Musa, G. SCUBA Diving Motivation. In Scuba Diving Tourism; Musa, G., Dimmock, K., Eds.; Routledge: New York, NY, USA, 2013; pp. 107-116. ISBN 9780128007228.

23. Kler, B.K.; Moskwa, E. Experience, interpretation and meanings. In Scuba Diving Tourism; Musa, G., Dimmock, K., Eds.; 2013; pp. 134-151. ISBN 9781136324949.

24. Thirumoorthy, T.; Wong, K.M.; Musa, G. SCUBA Diving Satisfaction. In Scuba Diving Tourism; Musa, G., Dimmock, K., Eds.; Routledge: New York, NY, USA, 2013; ISBN 9781136324949.

25. Ong, T.F.; Musa, G. SCUBA divers' underwater responsible behaviour: Can environmental concern and divers' attitude make a difference? Curr. Issues Tour. 2012, 15, 329-351. [CrossRef]

26. Toyoshima, J.; Nadaoka, K. Importance of environmental briefing and buoyancy control on reducing negative impacts of SCUBA diving on coral reefs. Ocean Coast. Manag. 2015, 116, 20-26. [CrossRef]

27. Ballantyne, R.; Packer, J.; Hughes, K. Tourists' support for conservation messages and sustainable management practices in wildlife tourism experiences. Tour. Manag. 2009, 30, 658-664. [CrossRef]

28. Giglio, V.J.; Luiz, O.J.; Chadwick, N.E.; Ferreira, C.E.L. Using an educational video-briefing to mitigate the ecological impacts of scuba diving. J. Sustain. Tour. 2018, 26, 782-797. [CrossRef]

29. Hammerton, Z.; Bucher, D. Levels of intervention-Reducing SCUBA-diver impact within subtropical marine protected areas. J. Ecotourism 2015, 14, 3-20. [CrossRef]

30. Rangel, M.O.; Pita, C.B.; Gonçalves, J.M.S.; Oliveira, F.; Costa, C.; Erzini, K. Developing self-guided scuba dive routes in the Algarve (Portugal) and analysing visitors' perceptions. Mar. Policy 2014, 45, 194-203. [CrossRef]

31. Hammerton, Z. Low-impact diver training in management of SCUBA diver impacts. J. Ecotourism 2016, 16, 69-94. [CrossRef]

32. Hein, M.Y.; Lamb, J.B.; Scott, C.; Willis, B.L. Assessing baseline levels of coral health in a newly established marine protected area in a global scuba diving hotspot. Mar. Environ. Res. 2015, 103, 56-65. [CrossRef] [PubMed]

33. Lamb, J.B.; True, J.D.; Piromvaragorn, S.; Willis, B.L. Scuba diving damage and intensity of tourist activities increases coral disease prevalence. Biol. Conserv. 2014, 178, 88-96. [CrossRef]

34. Andy, L.; Lee, R.-Y.; Tzeng, G.-H. Characteristics of Professional Scuba Dive Guides. Tour. Mar. Environ. 2014, 10, 85-100. [CrossRef]

35. Di Franco, A.; Milazzo, M.; Baiata, P.; Tomasello, A.; Chemello, R. Scuba diver behaviour and its effects on the biota of a Mediterranean marine protected area. Environ. Conserv. 2009, 36, 32-40. [CrossRef]

36. Delgado, J.P. The Impact on and Opportunities Arising from Tourism to Submerged Sites. In UNESCO Scientific Colloquium on Factors Impacting the Underwater Cultural Heritage; UNESCO, Ed.; Royal Library of Belgium: Brussels, Belgium, 2011 ; pp. 54-57. 
37. Chung, S.; Au, A.; Qiu, J.-W. Understanding the Underwater Behaviour of Scuba Divers in Hong Kong. Environ. Manage. 2013, 51, 824-837. [CrossRef]

38. Di Franco, A.; Baiata, P.; Milazzo, M. Effects of recreational scuba diving on Mediterranean fishes: Evidence of involuntary feeding? Mediterr. Mar. Sci. 2013, 14, 15-18. [CrossRef]

39. Santander Botello, L.C.; Propin Frejomil, E. Impacto ambiental del turismo de buceo en arrecifes de coral. Cuad. Tur. 2009, 24, 207-227.

40. Giglio, V.J.; Luiz, O.J.; Schiavetti, A. Recreational Diver Behavior and Contacts with Benthic Organisms in the Abrolhos National Marine Park, Brazil. Environ. Manag. 2016, 57, 637-648. [CrossRef]

41. Anderson, L.E.; Loomis, D.K. SCUBA Diver Specialization and Behavior Norms at Coral Reefs. Coast. Manag. 2011, 39, 478-491. [CrossRef]

42. Lucrezi, S.; Ferretti, E.; Milanese, M.; Sarà, A.; Palma, M. Securing sustainable tourism in marine protected areas: Lessons from an assessment of scuba divers' underwater behaviour in non-tropical environments. J. Ecotourism 2020. [CrossRef]

43. Roche, R.C.; Harvey, C.V.; Harvey, J.J.; Kavanagh, A.P.; McDonald, M.; Stein-Rostaing, V.R.; Turner, J.R. Recreational Diving Impacts on Coral Reefs and the Adoption of Environmentally Responsible Practices within the SCUBA Diving Industry. Environ. Manag. 2016, 58, 107-116. [CrossRef] [PubMed]

44. Uyarra, M.C.; Côté, I.M. The quest for cryptic creatures: Impacts of species-focused recreational diving on corals. Biol. Conserv. 2007, 136, 77-84. [CrossRef]

45. Giglio, V.J.; Luiz, O.J.; Ferreira, C.E.L. Ecological impacts and management strategies for recreational diving: A review. J. Environ. Manag. 2020, 256, 109949. [CrossRef] [PubMed]

46. DOF-Diario Oficial de la Federación. ACUERDO que Establece Como Zona de Refugio para la Protección de la Flora y Fauna Marinas, las Aguas Comprendidas en Los Arcos, Jalisco; SEMARNAT: Mexico City, Mexico, 1975; p. 1.

47. Aranda Mena, O.S. Lista Sistemática de los Peces de Arrecife de Bahía de Banderas; Universidad de Guadalajara: Jalisco-Nayarit, Mexico, 2000.

48. Medina-Rosa, P.; Cupul-Magaña, A. Los corales del área protegida Los Arcos: Sobrevivir a impactos humanos y naturales. Mexicoa 2001, 3, 86-91.

49. Medina-Rosas, P. El Efecto de las Actividades Turísticas Sobre los Corales Pétreos (Cnidaria, Anthozoa, Scleractinia) de los Arcos; Universidad de Guadalajara: Jalisco, Mexico, 1997.

50. Ramírez Cordero, C.A. Uso Ecoturístico y Capacidad de Carga de Buceo del Parque Nacional Islas Marietas y los Arcos de la Bahía de Banderas; Universidad de Guadalajara: Jalisco-Nayarit, Mexico, 2008.

51. SEMAR/DIGAOHM; Secretaria de Marina/Dirección General Adjunta de Oceanografía. Agenda Turística del Golfo y Pacífico Mexicano_Jalisco; Secretaría de Marina: Ciudad de México, Mexico, 2018.

52. Stokes, K.; Scammon, K.; Double, D.; Toon, K.; Hendricks, S.; Alfonso, A.; Jimenez, Z.; De La Pena, K.; Santos, K.C. Management of a Marine Park: Analysis of recreational and illegal fishing pressures on the reef fish assemblage at Los Arcos Reserve in Jalisco, Mexico. J. Fish. Life Sci. 2019, 4, 24-28.

53. Cochran, W.G. Sampling Techniques, 3rd ed.; John Wiley \& Sons: New York, NY, USA, 1977; ISBN 9781855736702.

54. Casal, J.; Mateu, E. Tipos De Muestreo. Rev. Epidem. Med. Prev 2003, 1, 3-7. [CrossRef]

55. Camp, E.; Fraser, D. Influence of conservation education dive briefings as a management tool on the timing and nature of recreational SCUBA diving impacts on coral reefs. Ocean Coast. Manag. 2012, 61, 30-37. [CrossRef]

56. Edney, J.L. Lust for Rust: Wreck Divers and the Management of Underwater Cultural Heritage; Southern Cross University: East Lismore, Australia, 2018.

57. Wiener, C.S. Understanding Spinner Dolphin Marine Tourism in Hawai'i: A Social Approach to Assessing Underwater Interactions; York University: Toronto, ON, Canada, 2016.

58. PADI. 2020 Instructor Manual; PADI, Ed.; Professional Association of Diving Instructors: Rancho Santa Margarita, CA, USA, 2020.

59. Jadot, C.; Bertuol, P.R.K.; Oliveira, G.; Krumholz, J.; de Leon, R. Intentional and accidental diver's contact to reefs at popular locations in the Dutch Caribbean. In Proceedings of the American Academy of Underwater Sciences 35th Symposium, Dauphin Island, AL, USA, 20-24 September 2016; Lobel, L., Lombardi, M., Eds.; American Academy of Underwater Sciences: Narragansett, PI, USA, 2016; pp. 74-85.

60. Rouphael, A.B.; Inglis, G.J. "Take only photographs and leave only footprints"?: An experimental study of the impacts of underwater photographers on coral reef dive sites. Biol. Conserv. 2001, 100, 281-287. [CrossRef]

61. Zar, J.H. Biostatistical Analysis, 4th ed.; Pearson Education India: Upper Saddle River, NJ, USA, 1999 ; ISBN 9788177585827.

62. Ong, T.F.; Musa, G. Examining the influences of experience, personality and attitude on SCUBA divers' underwater behaviour: A structural equation model. Tour. Manag. 2012, 33, 1521-1534. [CrossRef]

63. Luna, B.; Perez, C.V.; Sanchez-Lizaso, J.L. Benthic impacts of recreational divers in a Mediterranean Marine Protected Area. ICES J. Mar. Sci. 2009, 66, 517-523. [CrossRef]

64. Porbjörnsson, J.G.; Ólafsdóttir, J.H.; Kristjánsson, B.K.; Chambers, C.; Burns, G.L. Recreational scuba diving in a groundwater ecosystem: Disturbance mechanisms, ecological impacts and stakeholder perceptions. Aquat. Conserv. Mar. Freshw. Ecosyst. 2020, 30, 1012-1022. [CrossRef]

65. PADI. PADI Course Catalog. Available online: https: / $/$ www.padi.com $/$ courses?discipline=826\&experience-level=All\&type= All\&page $=3$ (accessed on 13 August 2020). 
66. Lucrezi Id, S.; Milanese, M.; Cerrano, C.; Palma, M. The influence of scuba diving experience on divers' perceptions, and its implications for managing diving destinations. PLOS ONE 2019, 14, e0219306. [CrossRef] [PubMed]

67. Richards, G.; Lénia, M.; Mein, K.; Marques, L.; Mein, K. Summary for Policymakers. In Climate Change 2013: The Physical Science Basis. Contribution of Working Group I to the Fifth Assessment Report of the Intergovernmental Panel on Climate Change; Stocker, T.F., Qin, D., Plattner, G.-K., Tignor, M., Allen, S.K., Boschung, J., Nauels, A., Xia, Y., Bex, V., Midgley, P.M., Eds.; Cambridge University Press: Cambridge, UK, 2013; pp. 3-29. ISBN 978-92-9169-138-8.

68. Barraza, E. Buceo responsable en El Salvador. Real. Reflex. 2018, 18, 13-20. [CrossRef]

69. Hawkins, J.P.; Roberts, C.M.; Van'T Hof, T.; De Meyer, K.; Tratalos, J.; Aldam, C. Effects of Recreational Scuba Diving on Caribbean Coral and Fish Communities. Conserv. Biol. 1999, 13, 888-897. [CrossRef]

70. Anthony, K.R.N.; Marshall, P.A.; Abdulla, A.; Beeden, R.; Bergh, C.; Black, R.; Eakin, C.M.; Game, E.T.; Gooch, M.; Graham, N.A.J.; et al. Operationalizing resilience for adaptive coral reef management under global environmental change. Glob. Chang. Biol. 2015, 21, 48-61. [CrossRef]

71. Barker, N.H.L.; Roberts, C.M. Scuba diver behaviour and the management of diving impacts on coral reefs. Biol. Conserv. 2004, 120, 481-489. [CrossRef]

72. Ward, C.; Stringer, L.C.; Holmes, G. Protected area co-management and perceived livelihood impacts. J. Environ. Manag. 2018, 228, 1-12. [CrossRef] 